\section{$\underset{\substack{\text { hommes } \\ \text { \& migrations }}}{ }$}

\section{Hommes \& migrations}

Revue française de référence sur les dynamiques

migratoires

\section{$1298 \mid 2012$}

France - Algérie, le temps du renouveau

\title{
Enono Anya
}

La musique en partage

\section{François Bensignor}

\section{(2) OpenEdition \\ 1 Journals}

Édition électronique

URL : http://journals.openedition.org/hommesmigrations/1595

DOI : 10.4000/hommesmigrations. 1595

ISSN : 2262-3353

Éditeur

Musée national de l'histoire de l'immigration

Édition imprimée

Date de publication : 1 juillet 2012

Pagination : 151-155

ISSN : 1142-852X

\section{Référence électronique}

François Bensignor, «Enono Anya », Hommes \& migrations [En ligne], 1298| 2012, mis en ligne le 29 mai 2013, consulté le 22 septembre 2020. URL : http://journals.openedition.org/hommesmigrations/ 1595 ; DOI : https://doi.org/10.4000/hommesmigrations.1595

Ce document a été généré automatiquement le 22 septembre 2020.

Tous droits réservés 


\title{
Enono Anya
}

\author{
La musique en partage
}

François Bensignor

1 Faire résonner les chants des îles de la Nouvelle-Calédonie en harmonie avec les mélodies et instruments du Sud marocain, telle était la gageure du projet Enono Anya. Quelques années d'approche, le choix des bons artistes, une résidence en deux temps sur chaque territoire, et le travail de création se voit couronné de succès. La fusion réussie sur le plan musical trouve son développement dans la reconnaissance mutuelle entre cultures des antipodes. Récit d'une création.

2 Les uns viennent des plaines où pousse l'arganier. Les autres sont issus d'un puissant clan de la mer. Kanaks des îles Loyauté, Imazighen du Souss marocain, leurs chansons auraient pu ne jamais se croiser. Pourtant ils ont franchi les océans qui les séparent, dans le but d'établir un fructueux dialogue dans le respect mutuel. Chaque groupe à sa manière exprime la vérité de sa culture, fier de sa propre identité. Et de cette rencontre jaillit une musique nouvelle, limpide comme le lagon turquoise, vive et gracieuse telle une danseuse du Souss arborant ses broderies et bijoux. L'art du voyage exprime sa quintessence créative dans la rencontre fusionnelle d'Enono Anya.

\section{Les instigateurs}

3 L'idée de ce dialogue est née de la rencontre entre le producteur calédonien Alain Lecante et le directeur artistique du festival Timitar, Brahim El Mazned. Ces deux passionnés de musique et d'échange vivent très concrètement leurs engagements respectifs dans la production, la valorisation et la diffusion internationales des musiques spécifiques aux mondes culturels dans lesquels ils évoluent. Le festival Timitar, dont Brahim El Mazned assure la direction artistique depuis sa fondation à Agadir en 2004, consacre une partie essentielle de sa programmation aux traditions musicales amazigh (cf. H\&M, $n^{\circ} 1263$ ).

Quant à Alain Lecante, il produit les artistes les plus marquants du kanéka, genre musical inventé par les nouvelles générations de Kanaky, à l'initiative de Jean-Marie 
Tjibaou, penseur et bâtisseur d'une nouvelle dignité culturelle pour le peuple kanak (cf. $\mathrm{H} \& \mathrm{M}, \mathrm{n}^{\circ}$ 1277).

5 Se conformant à la devise du festival Timitar, "Les artistes amazigh accueillent les musiques du monde", Brahim El Mazned est l'un des rares et tout premiers programmateurs de l'hémisphère Nord à présenter des artistes de kanéka au public de son festival.

6 À la curiosité éclairée de son goût artistique aimant prendre des risques s'ajoute un élément humain fortuit mais déterminant pour la bonne mise en œuvre du projet Enono Anya. Alain Lecante, fils d'un fonctionnaire français, est né à Agadir. Son rapprochement avec le festival Timitar et son directeur se fait ainsi dans un mouvement naturel. Prendre le festival pour partenaire relève aussi pour lui d'une forme de retour à l'univers qui a bercé sa prime enfance. Cet élément d'humanité donne le "la" du travail de rencontre artistique. Témoin le nom du groupe rassemblant les artistes des deux cultures. "Enono" signifie "rassembler", "partager", en langue nengoné de l'île de Maré, Nouvelle-Calédonie. "Anya" désigne la "note de musique" dans la langue amazigh des Berbères du Maroc. Enono Anya peut se traduire par: "la musique en partage".

7 Deux bonnes années d'approches, de réflexions communes et de préparation ont été nécessaires avant la mise en œuvre du projet. Ce temps de maturation sert à réunir les partenaires et financeurs*, à choisir les musiciens participant à l'expérience. Premier critère de sélection des artistes : ceux-ci doivent d'abord ancrer leur travail musical au cœur de traditions culturelles représentant leurs peuples respectifs. Autre important critère : le fait qu'ils aient l'esprit assez ouvert pour accepter la cohabitation avec des musiciens aux habitudes culturelles et cultuelles très éloignées des leurs. Enfin, bien entendu, ils doivent présenter des qualités artistiques d'un bon niveau professionnel. Le choix s'arrête sur quatre musiciens marocains, anciens membres du groupe Amarg Fusion, et les Calédoniens du groupe Sumaele.

\section{L'équipe marocaine}

8 Issu de la jeune scène marocaine, le groupe Amarg Fusion a réussi l'une des plus audacieuses expériences de mélange jamais tentée avec le genre emblématique du sud du pays. Initié auprès de vieux rwayes, bardes berbères, maîtres poètes-chanteurs traditionnels, Ali Faiq a mené l'entreprise avec finesse. À la tête de leurs troupes itinérantes, les rwayes transportaient autrefois messages et nouvelles de par les douars, informant les petites communautés paysannes éparpillées dans les campagnes. Aujourd'hui, leurs poèmes figurent au répertoire de nombreux jeunes artistes. Il n'est guère de tradition vivante qui soit encore si populaire et respectée aujourd'hui au Maghreb.

9 Forts du travail réalisé avec Amarg Fusion, Ali Faiq et les trois musiciens participant à l'aventure - Abdellah Aït El Moudden (rebab, lôtar), Rahal Bou Aaddi (guitare basse, lôtar), Mohamed Bou Nit (percussions) - parviennent à préserver la beauté expressive originelle de l'art des rwayes dans leur rencontre avec Sumaele. Les instruments traditionnels acoustiques marocains - le ribab, petite vièle monocorde au son puissant, et le lôtar, petit luth à trois ou quatre cordes - trouvent leur place auprès de la guitare, de la basse électrique et des percussions. La voix d'Ali, tout en souplesse, module la généreuse poésie de l'amarg au gré de l'échelle pentatonique traditionnelle. Le 
sentiment de nostalgie qu'elle diffuse se mêle avec délice aux harmonies des voix issues du chant des vagues sur les rivages coralliens de la Mélanésie.

\section{Le groupe Sumaele}

Constitué par les trois frères Wahnunu - Georges (voix, chœurs, bambou), François (guitare, voix, chœurs), Mathias (voix, chœurs) - et leurs femmes - Messaline, Élisa, Rolande, aux voix et chœurs -, Sumaele excelle dans l'harmonie vocale. Le chant polyphonique à trois ou quatre voix est une spécialité des îles Loyauté, notamment de Maré. Son originalité jaillit du placement des intervalles entre les voix et de la ligne mélodique suivie par chacune d'elles. Hérités d'anciennes traditions, les secrets de cette science de l'harmonisation se sont transmis de bouche à oreille. Les pasteurs protestants, évangélisateurs de l'archipel à partir de Maré, y ont greffé leurs cantiques religieux. C'est de cette symbiose que sont issus les "taperas" - nom dérivé de "chant de tempérance".

11 Et leur pratique, très vivante, s'est propagée des îles Loyauté à la Grande Terre. Formés dès leur enfance aux traditions des taperas, les frères Wahnunu vont emprunter la voie du kanéka, ouverte par leurs aînés vers la fin des années quatre-vingt. Cette nouvelle musique, accompagnant la lutte politique du peuple kanak pour l'affirmation de sa culture, va contribuer à sa reconnaissance.

Les frères Wahnunu vont vivre l'aventure du groupe Gulianod, cofondé par l'aîné Georges. Ensemble ils mettent en valeur le style mélodique du kanéka des îles, sur le rythme du "tchap". Et, quand plusieurs des jeunes musiciens quittent Gulianod après s'être mariés, les trois frères se regroupent en famille avec leurs épouses pour former Sumaele.

\section{Le travail de création}

13 Enono Anya est le fruit d'une résidence de création. Fin mai 2012, les musiciens marocains s'envolent pour la Nouvelle-Calédonie. "C'était une grande première pour moi. J'ai découvert la culture kanak avec sa musique et ses polyphonies vocales, le ukulélé tel qu'il est joué en Nouvelle-Calédonie, mais aussi de nouvelles structures pour construire des chansons", explique Ali Faiq. Les Marocains font alors l'expérience de la coutume chère aux Kanaks. "À travers la coutume, c'est la notion de respect qui guide notre société. La maison appartient à une famille. Avant d'y entrer, on présente une coutume : Ali a pu le voir", commente Mathias Wahnunu.

Accueillis à Nouméa au Centre culturel Tjibaou, les deux groupes vont préparer un répertoire original à partir de leurs chansons respectives. "Chacun des groupes a apporté plusieurs de ses morceaux. Une sélection a été faite et nous avons travaillé avec Camel Zekri pour faire naître de nouveaux morceaux issus du mélange", poursuit Mathias. Chargé de la direction artistique de la création, Camel Zekri joue un rôle essentiel lors de la mise en forme musicale du répertoire. Ce musicien doué d'une curiosité sans limite possède une faculté d'écoute hors du commun. Premier prix de guitare classique, diplômé de musicologie, il s'est forgé en France une réputation d'improvisateur en musique expérimentale. Sa carrière prend une tournure inédite quand son grand-père, maître du Diwân de Biskra en Algérie, lui transmet l'héritage de 
son art (cf. $\mathrm{H \& M}, \mathrm{n}^{\circ}$ 1285). La cérémonie du diwân, semblable à celle des Gnaoua au Maroc, trouve un nouveau terrain d'expression. Avec sa troupe, Camel Zekri parcourt le Sahel et l'Europe. Ses productions artistiques pour les albums de grandes voix africaines - Hasna (Algérie), Malouma (Mauritanie), Mamar Kassey (Niger) et Oudaden (Maroc) - le posent en passeur éclairé, capable de tisser des liens d'une grande profondeur entre traditions orales et musiques globales. Son expérience calédonienne avec Dick \& Hnatr pour leur album Angaïshola lui ouvre de nouveaux horizons qu'il explore brillamment pour le projet Enono Anya.

Ali Faiq décrit ainsi la démarche de création: "Tout le monde écoute le morceau proposé, à la suite de quoi chacun apporte des idées pour le développer. Camel Zekri, le directeur artistique, nous a beaucoup aidés à sélectionner les meilleures idées et à les intégrer aux différents morceaux. Pour les passages de création, on va d'abord s'interroger sur le thème de la chanson, afin d'en extraire les mots clés, que chacun va tenter de reformuler dans sa langue en paroles fluides, dont le sens correspond à l'esprit du texte original. Parfois l'état d'esprit est si bien traduit que l'on n'a même pas l'impression de passer d'une langue à l'autre. Le rapprochement est alors saisissant. Ces deux cultures que l'on aurait pu penser très éloignées l'une de l'autre paraissent soudain très proches. Depuis cette expérience, je crois vraiment à l'inconscient collectif. Autrefois, je l'entendais à travers la musique, maintenant je le vis de l'intérieur."

16 À la polyphonie fervente des taperas, hérités des chorales océaniennes, s'enchaînent harmonieusement les mélodies berbères en variations pentatoniques. Chants et rythmes s'unissent en étreintes fluides, dans le respect des identités musicales de chacun. "On peut expliquer cette fluidité par l'esprit d'ouverture qui préside à chacun de nos deux groupes, souligne Ali. Elle exprime le respect de chacun envers l'autre. Un équilibre s'est établi à partir des points forts de chacun. Sumaele apporte la polyphonie vocale, le rythme et les arpèges de la guitare, ainsi que le tempo marqué sur le bambou. De notre côté, nous apportons les instruments traditionnels du Souss marocain, qui sont fabriqués à la main, le ribab et le lôtar. Même si notre musique est pentatonique, nous avons cette volonté de dépasser les limites qui s'imposent dans notre style. Si cette expérience est réussie, nous le devons beaucoup à Camel Zekri, qui est intervenu comme arrangeur. Il nous a beaucoup aidés à établir l'équilibre qui préside à cette fusion musicale." "Comme le disent nos amis de Sumaele : 'Il y a une lumière dans le travail que nous avons fait', poursuit Ali. Celle-ci provient du respect de nos différences et de la valorisation de nos points communs. La musique est universelle. Elle n'a pas de frontières. Mais parfois les cultures érigent des frontières. Les membres des deux groupes ont abaissé ces frontières pour aller vers les autres. Cette création est le fruit d'un partage mutuel. Les passages d'une musique à l'autre se font naturellement, au point que nous nous sentons appartenir au même groupe. Il n'y a plus d'un côté des Calédoniens et des Marocains de l'autre, nous sommes un groupe qui intègre les musiques de ces deux cultures. Nous sommes des citoyens du monde, qui avons le sentiment profond de partager nos spécificités. Dans ce projet, nous nous sentons tous à égalité, sans qu'une personne ne domine les autres. Et cette philosophie nous a beaucoup aidées à réussir ce projet." 


\section{La diffusion}

Après les cinq concerts donnés en Nouvelle-Calédonie, à Koné, Koumac et Nouméa, pour clore la première partie de leur résidence, tous les musiciens d'Enono Anya se retrouvent à Agadir début juillet 2012. Avec l'aide du coach scénique Alain Osowski, ils travaillent alors à l'amélioration de la dimension spectacle du répertoire créé à Nouméa. Massé devant l'une des grandes scènes du festival Timitar, le public marocain réserve un accueil enthousiaste à cette création, malgré le scepticisme qu'elle avait pu susciter à l'origine. "Avant notre départ pour la Nouvelle-Calédonie, des personnes nous ont affirmé qu'il serait impossible de fusionner notre style à celui des Kanaks, explique Ali. Mais nous nous sommes donné la preuve à nous-mêmes qu'au contraire c'est tout à fait possible. Personnellement, j'ai beaucoup appris de cette expérience. Depuis des années, je continue d'apprendre, mais ce que j'ai appris au cours de ces jours de résidence passés à Nouméa est d'une richesse énorme, dont j'ai ramené les fruits." "L'un des objectifs de cette résidence consiste à faire aimer nos cultures respectives. C'est aussi une manière de les préserver. Celui qui ferme sa porte et coupe toute relation avec l'extérieur verra sa culture mourir. Nous sommes dans le monde de l'Internet. Si nos enfants constatent que d'autres peuples aiment et préservent leur culture, ils en feront de même pour la leur. Rassembler la culture kanak et la culture amazigh à travers Enono Anya est un moyen à la fois de préserver notre culture, notre patrimoine, et de les faire aimer par d'autres. Nous sommes conscients que beaucoup de choses dans notre patrimoine sont en voie de disparition, sur le plan musical ou poétique. Cette expérience peut constituer un petit clin d'œil sur ce que l'on peut partager. Et je veux souligner qu'il faut que ce partage soit sincère, spontané, propice à l'émotion."

\section{ANNEXES}

Coproducteurs : Festival Timitar (Agadir, Maroc), Centre culturel Tjibaou (Nouméa, Nouvelle-Calédonie), Mangrove Productions (Nouméa, Nouvelle-Calédonie)

Partenaires : Le Poemart (Pôle export de la musique et des arts de Nouvelle-Calédonie), la Sacenc (Société des auteurs compositeurs éditeurs de Nouvelle-Calédonie) et le Chapitô (structure itinérante de diffusion en Nouvelle-Calédonie). 